\title{
Oxidation Start Detection on Heating Parts of Thermogravimetry Curves for High Temperature Alloys Based on Nickel, Cobalt or Iron
}

\author{
Patrice Berthod*
}

Institut Jean Lamour (UMR CNRS 7198), Department 2 - Chemistry and Physics of Solids and Surfaces, Team 206, University Henri Poincaré Nancy 1, B.P. 70239, 54506 Vandoeuvre-lès-Nancy, France

\begin{abstract}
The heating parts of thermogravimetry curves performed for cast alloys in air at high temperatures were analysed, after correction from the effects of air buoyancy variation, to characterize the transient oxidation before reaching the targeted temperature for the isothermal stage usually applied thereafter. This was done here for three binary $\mathrm{M}-30 \mathrm{Cr}$ alloys, six ternary M-30Cr-0.4 and $0.8 \% \mathrm{C}$ alloys, and three $\mathrm{M}-30 \mathrm{Cr}-0.4 \mathrm{C}-6 \mathrm{Ta}$ quaternary alloys, heated in synthetic air at $20 \mathrm{~K}$ min-1 until 1000,1100 or $1200^{\circ} \mathrm{C}$. The cobalt alloys begin to be oxidized with a sufficient mass gain to be detected by thermogravimetry, earlier than the nickel or iron alloys (i.e. at lower temperatures). The temperature of oxidation start is lowered by the presence of tantalum for the three families of alloys. When the carbon content (or the carbides density) increases in the alloy, the temperature of oxidation start decreases for the cobalt alloys and remains almost constant for the nickel or iron alloys, while the total mass gain due to oxidation during heating increases for the nickel and cobalt alloys and decreases for the iron alloys.
\end{abstract}

Keywords: Nickel alloys, cobalt alloys, iron alloys, tantalum, carbides, high temperature, oxidation at heating.

\section{INTRODUCTION}

Pieces made of refractory alloys or superalloys for use at high temperatures are generally exposed to either hot gases or molten aggressive substances [1-4]. This inevitably induces a more or less rapid deterioration of their surfaces. They need to be isolated from such atmospheres or corrosive deposits by a protective continuous external oxide scale spontaneously formed thanks to either the addition in the alloys' chemical composition of sufficient quantities in elements among aluminum, chromium or silicon, or the presence of a protective coating also containing high contents in one or several of the same elements ( $\mathrm{Al}, \mathrm{Cr}$ and/or Si) [4-5]. Such alloys are then rapidly covered by an external continuous protective oxide layer, which lowers the oxidation rate because of a slow Wagner's parabolic kinetic [6]. This one is governed by the diffusion of the species involved in the oxidation phenomenon, through the thickening external oxide scale. The parabolic constant, which is particularly low if the external oxide is stoichiometric (e.g. chromia, alumina), allows predicting the behaviour on long term.

Before such isothermal oxidation progress, the first oxide generally appears on the alloy's surface during the heating before the isothermal exposition to high temperature, by nucleation and simultaneous lateral growth and perpendicular thickening [4]. This becomes detectable by mass gain measurement at a temperature which can vary with the nature of the alloy, its chemical composition (especially the contents of the most oxidable elements

*Address correspondence to this author at the Institut Jean Lamour (UMR CNRS 7198), Department 2 - Chemistry and Physics of Solids and Surfaces, Team 206, University Henri Poincaré Nancy 1, B.P. 70239, 54506 Vandoeuvre-lès-Nancy, France; Tel: (+33) 3836846 66; Fax: (+33) 383 6846 11; E-mail: Patrice.Berthod@lcsm.uhp-nancy.fr present in the alloy) and its microstructure (single-phased, multi-phased, grain size, dentritic orientation). The purpose of this work is precisely to characterize the start of oxidation on the surfaces of refractory alloys belonging to different families, when they are subjected to a heating up to high temperatures with the same rate and the same atmosphere for all, and to examine if their chemical compositions and microstructures may have an influence.

\section{MATERIALS AND METHODOLOGY}

\section{The Studied Alloys}

The twelve alloys considered in this work are of three types: four nickel-based alloys, four cobalt-based alloys and four iron-based alloys. For each base element $(\mathrm{M}=\mathrm{Ni}$, Co or $\mathrm{Fe})$, there are a binary alloy $(\mathrm{M}-30 \mathrm{wt} . \% \mathrm{Cr})$, two ternary alloys (M-30Cr-0.4C and $\mathrm{M}-30 \mathrm{Cr}-0.8 \mathrm{C}$ ) and a quaternary alloy (M-30Cr-0.4C-6Ta). Their exact chemical compositions, measured by microanalysis, are given in Table $\mathbf{1}$.

These alloys were obtained by a foundry process, from pure elements (Alfa Aesar: $\mathrm{Ni}, \mathrm{Cr}, \mathrm{Ta}$; and $\mathrm{C}$ graphite, purity higher than $99.9 \mathrm{wt} . \%$ ): melting by high frequency induction $(300 \mathrm{kHz}$, CELES furnace) in an inert atmosphere (pure argon, 300mbars). The ingots (about $100 \mathrm{~g}$ for each alloy) were solidified in the same water-cooled copper crucible in which their fusion was realized. Their microstructures are illustrated in Fig. (1) for the nickel-based alloys, Fig. (2) for the cobalt-based alloys and Fig. (3) for the iron-based alloys, by micrographs taken using a Scanning Electron Microscope (SEM, Philips model XL30) with the Back Scattered Electrons mode (BSE). The binary alloys are single phased, the ternary alloys contain in addition chromium carbides which appear darker than matrix: $\mathrm{Cr} 7 \mathrm{C} 3$ for the nickel alloys and $\mathrm{Cr} 23 \mathrm{C} 6$ for the cobalt-based and iron-based alloys (identified by Wavelength Dispersion Spectrometry, Cameca 
Table 1. Chemical Compositions (wt.\%) of the Studied Alloy (WDS Microanalysis)

\begin{tabular}{|c|c|c|c|}
\hline Name & Cr & C & Ta \\
\hline \hline \multicolumn{3}{|c|}{ Nickel-Based Alloys } \\
\hline Ni30Cr & 30 & $/$ & $/$ \\
\hline Ni30Cr0.4C & 30 & 0.4 & $/$ \\
\hline Ni30Cr0.8C & 30 & 0.8 & $/$ \\
\hline Ni30Cr0.4C+Ta & 31 & 0.4 & 5.4 \\
\hline \multicolumn{3}{|c|}{ Cobalt-Based Alloys } \\
\hline Co30Cr & 30 & $/$ & $/$ \\
\hline Co30Cr0.4C & 30 & 0.4 & $/$ \\
\hline Co30Cr0.8C & 30 & 0.8 & $/$ \\
\hline Co30Cr0.4C+Ta & 30 & 0.4 & 5.2 \\
\hline Iron-Based Alloys \\
\hline Fe30Cr & 30 & $/$ & $/$ \\
\hline Fe30Cr0.4C & 30 & 0.4 & $/$ \\
\hline Fe30Cr0.4C+Ta & 30 & 0.8 & $/$ \\
\hline
\end{tabular}
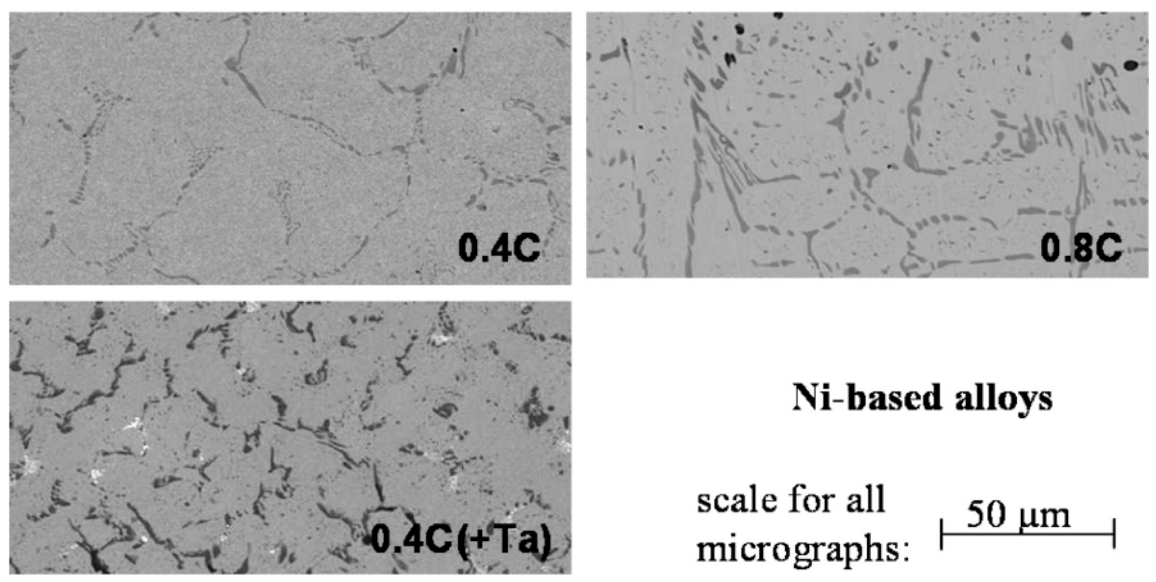

SX100 microprobe). The Ta-containing nickel-based alloy contains both chromium carbides and $\mathrm{TaC}$ carbides (whiter than matrix while the Ta-containing cobalt-based and ironbased alloys only contain $\mathrm{TaC}$ carbides.

Three parallelepipeds (for heating up to 1000,1100 and $1200^{\circ} \mathrm{C}$ ) were cut per alloy (volume less than $0.5 \mathrm{~cm} 3$ ) in the ingots. Their six main faces were polished with 1200-grit papers, with smoothing of their edges and corners with the same paper.

\section{Thermogravimetric Experiments; role of the Archime-} des' thrust Variation

Each sample was heated at $20 \mathrm{~K} \mathrm{~min}^{-1}$ from room temperature up to the targeted one, with recording of the mass gain, using a Setaram TGA 92 thermobalance. At the beginning of the heating the mass gain variation is generally not clear since the apparatus is not yet at thermal equilibrium (gas flow, sample, alumina-gained platinum suspension, ...). However, after heating over two or three hundreds Kelvin, the \{sample + suspension $\}$ mass increases linearly with time, although the temperature is not high enough to induce significant oxidation. This apparent increase in mass is to be attributed to the decrease in Archimede's thrust induced by the increase in temperature. If one writes the perfect gases' law for two temperatures, $\mathrm{T}_{0}$ (fixed, $298 \mathrm{~K}$ for example) and $\mathrm{T}$ (variable), for a gas pressure $\mathrm{P}$ supposed remaining equal

\section{Ni-based alloys}

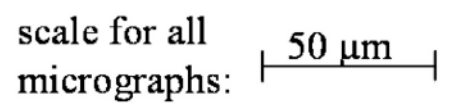

Fig. (1). Microstructures of the studied Nickel-based alloys (SEM/BSE micrographs).
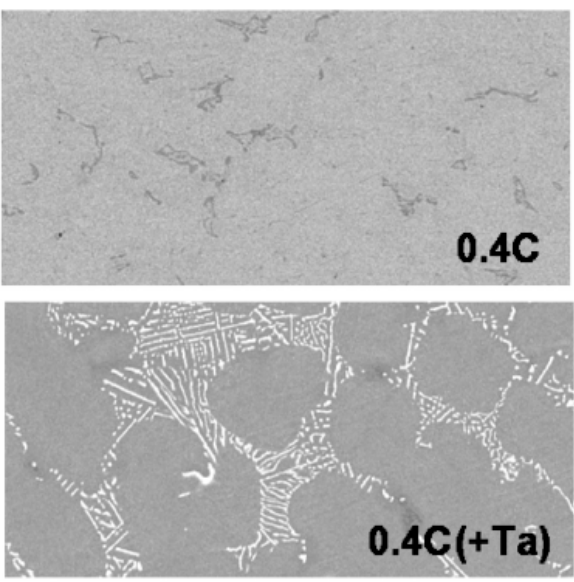

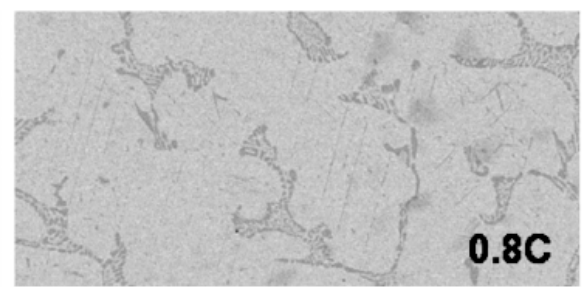

\section{Co-based alloys}

Fig. (2). Microstructures of the studied Cobalt-based alloys (SEM/BSE micrographs). 

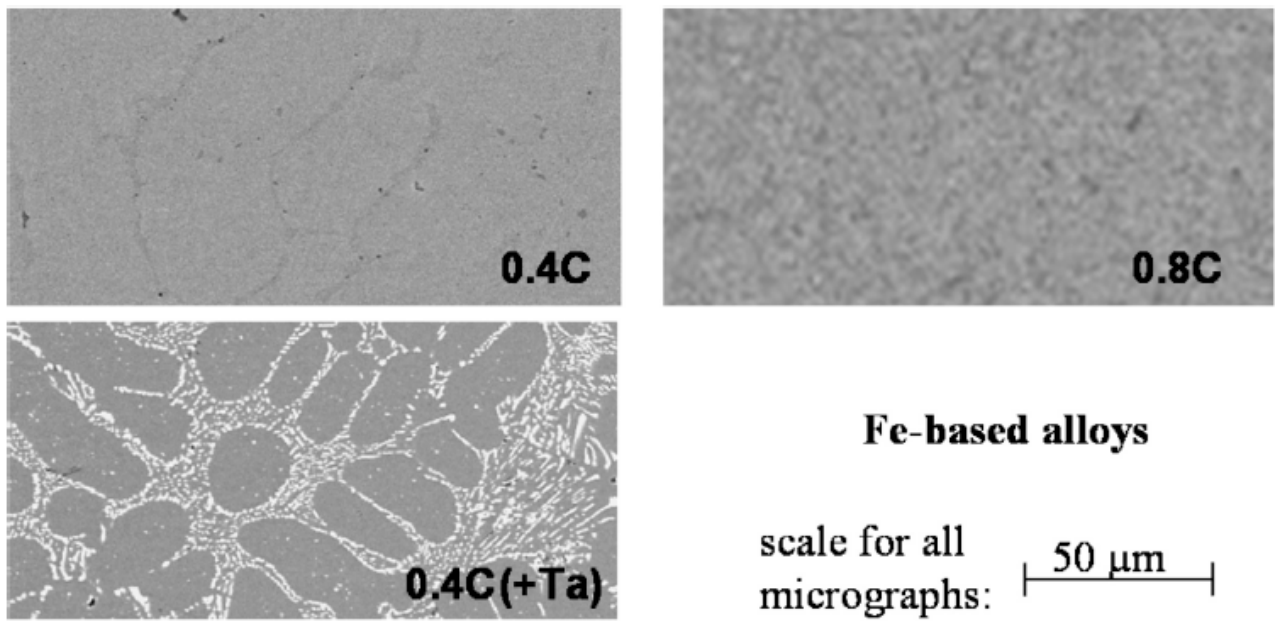

\section{Fe-based alloys}

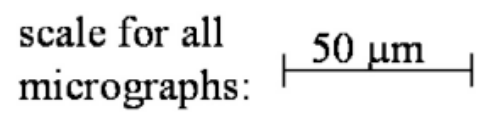

Fig. (3). Microstructures of the studied Iron-based alloys (SEM/BSE micrographs).

to $10^{5} \mathrm{~Pa}$ independently on temperature (this is the case in the hot part of the thermobalance used here), one obtains the equation (E1) which gives the volume mass of air $\left(\rho_{\mathrm{g}}\right)$ at $\mathrm{T}$ from its value at $\mathrm{T}_{0}$. The apparent mass $(\mathrm{m}$ ') of the sample measured by the thermobalance is equal to the real mass (m) subtracted by the contribution of the Archimedes' thrust (E2). Equation (E2), written for $\mathrm{T}$ and for $\mathrm{T}_{0}$, leads to a third equation (E3), then a fourth one (E4) if one replaces the volume mass of air at $\mathrm{T}$ by its expression given by (E1). Equation (E4) now shows that there is a positive difference of measured mass, which increases with temperature from $\mathrm{T}_{0}$.

$$
\begin{aligned}
& \rho(T)=\left(\frac{T_{0}}{T}\right) \times \rho\left(T_{0}\right) \\
& m^{\prime}(T)=m-V \times \rho_{g}(T) \\
& m^{\prime}(T)=m^{\prime}\left(T_{0}\right)+V \times\left(\rho_{g}\left(T_{0}\right)-\rho_{g}(T)\right) \\
& m^{\prime}(T)-m^{\prime}\left(T_{0}\right)=V \times \rho_{g}\left(T_{0}\right) \times\left(1-\left(\frac{T_{0}}{T}\right)\right) \\
& =V \times \rho_{g}\left(T_{0}\right) \times\left(\frac{T-T_{0}}{T}\right)
\end{aligned}
$$

(V: volume of sample+suspension, and m: real mass of sample+suspension)

As shown by Fig. (4), in which $\left(\mathrm{T}-\mathrm{T}_{0}\right) / \mathrm{T}$ is plotted versus $\mathrm{T}$, when $\mathrm{T}$ just starts its increase from ambient temperature $\left(\mathrm{T}-\mathrm{T}_{0}\right) / \mathrm{T}$ varies rapidly, while, when $\mathrm{T}$ has become higher than around $873 \mathrm{~K},\left(\mathrm{~T}-\mathrm{T}_{0}\right) / \mathrm{T}$, and then $\mathrm{m}^{\prime}(\mathrm{T})-\mathrm{m}^{\prime}\left(\mathrm{T}_{0}\right)$, vary slowly and linearly. Thus, when $\mathrm{T}$ has become high enough, if the mass gain accelerates and quits this linearity, this reveals a real mass gain due to a beginning of significant oxidation. This can be compared with the experimental thermogravimetric curve obtained in a real experiment with an inert alumina sample (no oxidation then no real mass gain) with almost the same geometry (notably surface and volume as most of the samples of studied alloys), instead of a real sample. One can see that there are some variations in the heating part when temperature is not yet high enough (thermal equilibrium is establishing), but which are thereafter followed by seemingly the same mass variation as reproduced by the curve representing $\left(\mathrm{T}-\mathrm{T}_{0}\right) / \mathrm{T}$. In addition, during the whole cooling, the experimental curve corresponds much better to the $\left(\mathrm{T}-\mathrm{T}_{0}\right) / \mathrm{T}$ variation.

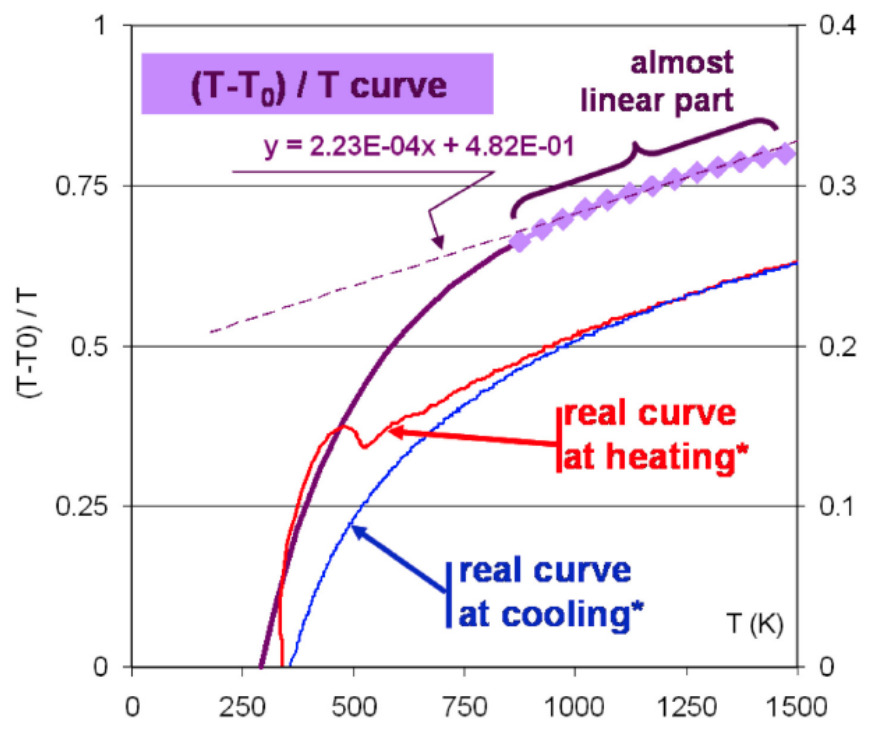

Fig. (4). Type of evolution of $\left(T-T_{0}\right) / T$ (i.e. of m' $(T)-m^{\prime}\left(T_{0}\right)$, yaxis on the left side) versus temperature; comparison with the heating part (thermal equilibrium not yet established at low temperature) and the cooling part (thermal equilibrium well established) of an experimental thermogravimetry curve obtained with an inert $\left(\mathrm{Al}_{2} \mathrm{O}_{3}\right)$ specimen with the same volume as the studied samples (y-axis on the right side, unit: $\mathrm{mg} / \mathrm{cm}^{2}$ ).

\section{Treatment and Exploitation of the Mass Gain Files}

Fig. (5) illustrates the method used for characterizing the start of oxidation at heating. A preliminarily correction was applied to the mass gain curve, which is here plotted versus temperature (instead of time) for evidencing the successive phenomena (a). The latter ones are: firstly an increase in mass gain at heating (effect of Archimede's thrust variation then acceleration of mass gain by real oxidation), secondly the isothermal mass gain (generally by transient oxidation quickly replaced by a parabolic kinetic), and finally a decrease in mass (inverse effect of Archimedes' thrust at cooling, eventually followed by rapid mass loss in case of oxide spallation). This correction begins by the 
determination of the equation of the linear part of the thermogravimetric curve recorded during the heating (decrease in Archimede's thrust, (b)), and thereafter this linear expression is subtracted to the measured mass, with as consequence a heating part of the curve now horizontal and lying along the temperature axis (c). Finally, zooming the end of the heating part of the corrected thermogravimetric curve allows distinguishing the start of mass gain due to real oxidation, with notably determination of the temperature of oxidation's start, and measurement of the total mass gain due to only oxidation during the whole heating.

\section{RESULTS}

Some examples of \{end of heating\} parts of the thermogravimetric curves are displayed in Fig. (6) for the nickel-based alloys, Fig. (7) for the Cobalt-based alloys and Fig. (8) for the iron-based alloys. In the three figures, concerning in each case the binary alloy (i.e. the more simple one among the four alloys) and the Ta-containing carbidesreinforced alloy (the more complex one), the three curves corresponding to the three targeted isothermal temperatures are plotted together $\left(1000,1100\right.$ and $\left.1200^{\circ} \mathrm{C}\right)$.

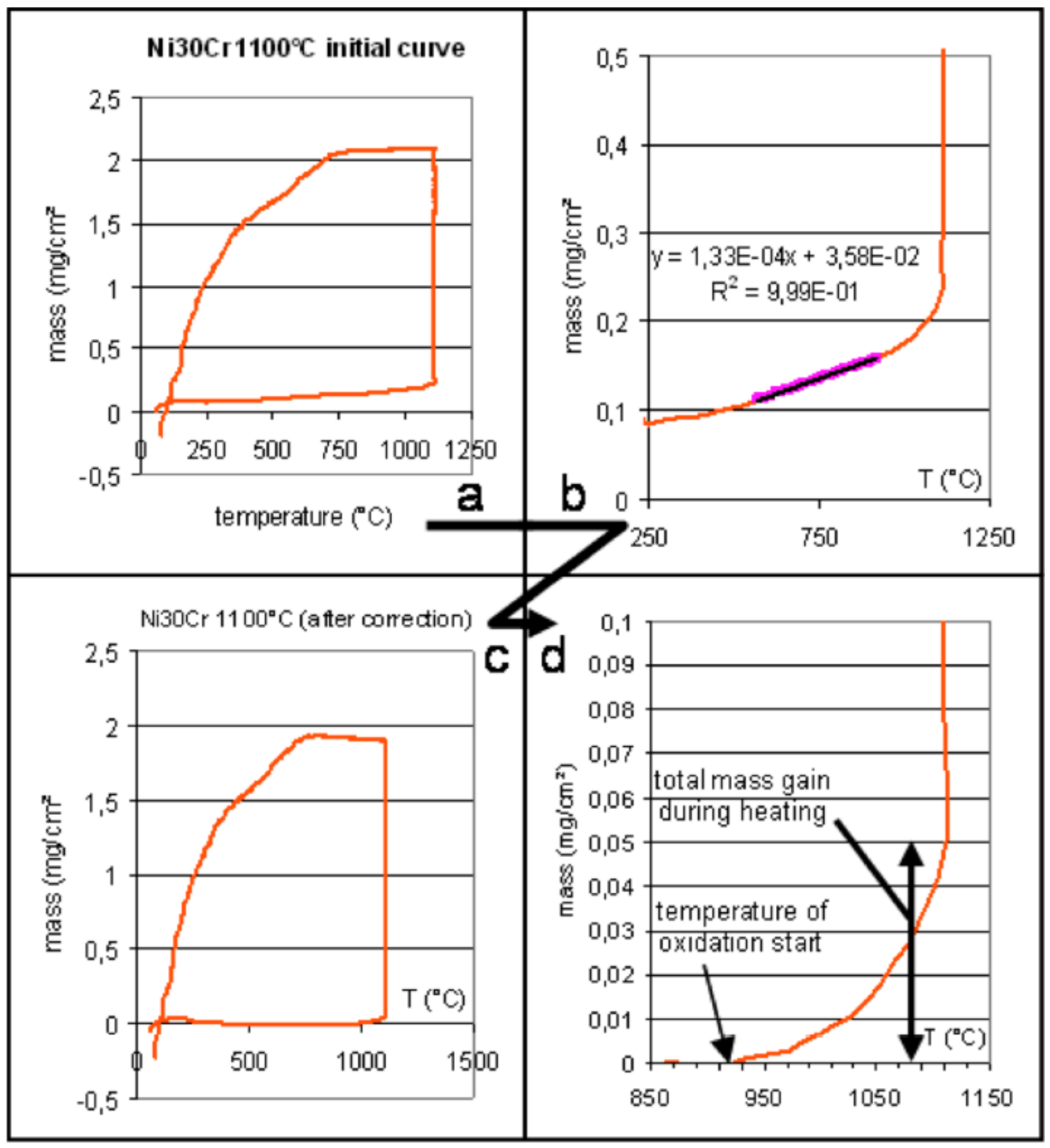

Fig. (5). Illustration of the treatment performed on the thermogravimetric records: a: the initial curve represented by a \{mass gain versus temperature \} - plot. b: zooming of the heating curve and equation of the linear part for correcting from the Archimedes' thrust. c: the whole curve after this correction. d: new zooming of the heating curve, visualization of oxidation start, and measurement of the temperature of oxidation start and of the mass gain achieved by oxidation during the heating. 

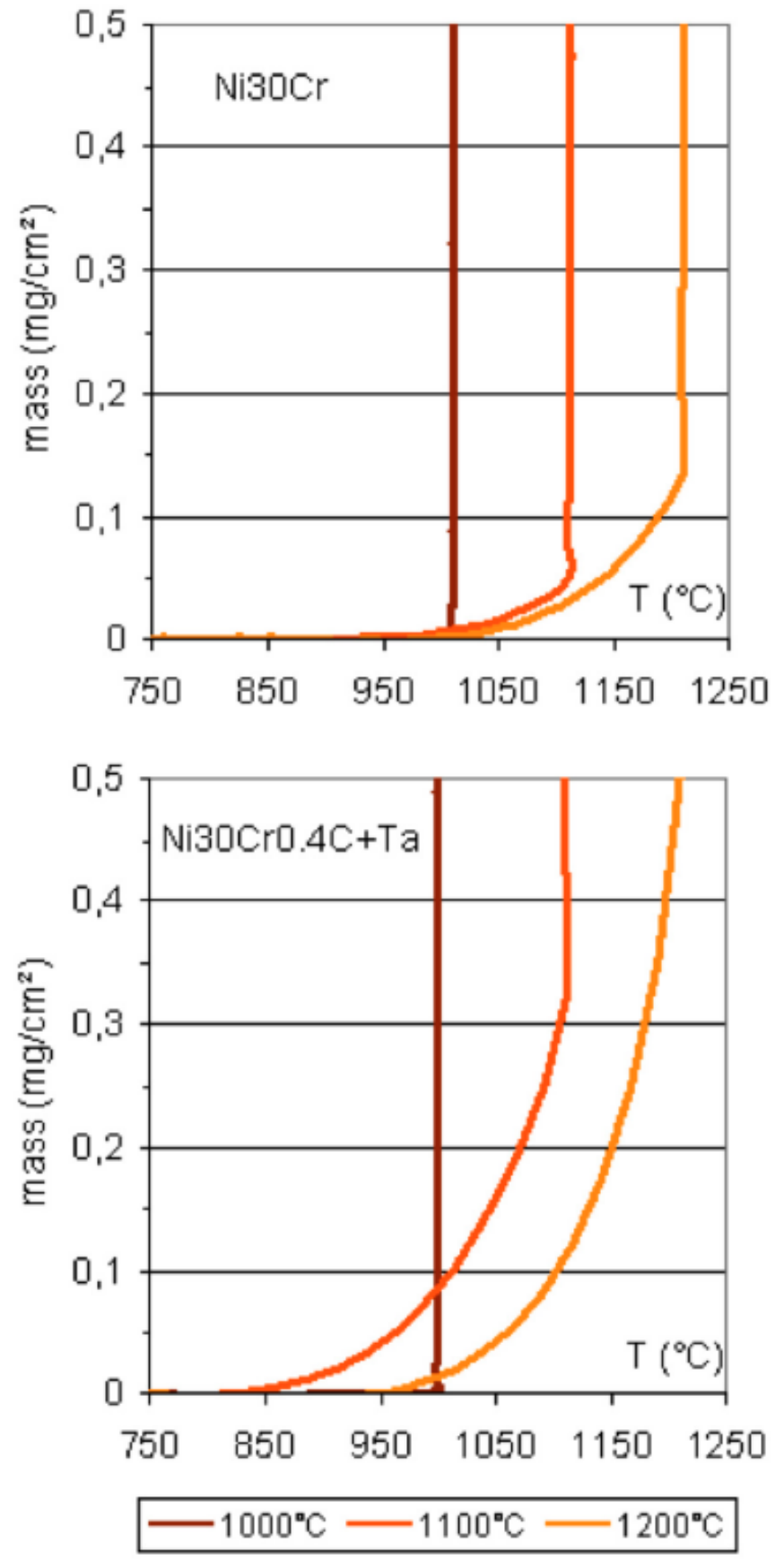

Fig. (6). Starts of mass gain due to oxidation during the last part of heating in the case of two of the Nickel-based alloys for the three tests (targeted isothermal temperatures equal to 1000,1100 and $\left.1200^{\circ} \mathrm{C}\right)$.

If for some alloys, the mass gain due to oxidation at heating started at almost the same temperature for the three tests (e.g. the three binary alloys, Ni-30Cr-0.4C, Co-30Cr$0.4 \mathrm{C}+\mathrm{Ta}, \mathrm{Fe}-30 \mathrm{Cr}-0.8 \mathrm{C}, \ldots)$, independently of the targeted temperature, it can be also seen that there is not the case for other alloys (e.g. Ni-30Cr- $0.4 \mathrm{C}+\mathrm{Ta}, \mathrm{Co}-30 \mathrm{Cr}-0.8 \mathrm{C}, \ldots$ ). This good reproducibility, or on the contrary lack of reproducibility, led to low or significant values of the standard deviation calculated from the three results and displayed as uncertainty bars in the histogram presented in Fig. (9). In the same histogram, the main purpose of which is to represent the evolution of the temperature of oxidation start versus the alloy family and versus the $\mathrm{C}$ and $\mathrm{Ta}$ contents, one can clearly see that the temperature of oxidation start is generally lower for the cobalt alloys than for the other alloys. In addition, in the cobalt-based family it seems that this temperature of oxidation start decreases when the carbon content increases. In contrast, there is no systematic difference between, on the one hand the ironbased family and on the other hand the nickel-based family, and among the four alloys in each family (no real dependence on the carbon content). However, when tantalum is added to the alloys containing $0.4 \mathrm{C}$, there is a tendency for a decrease in temperature of oxidation start, for the three base elements.
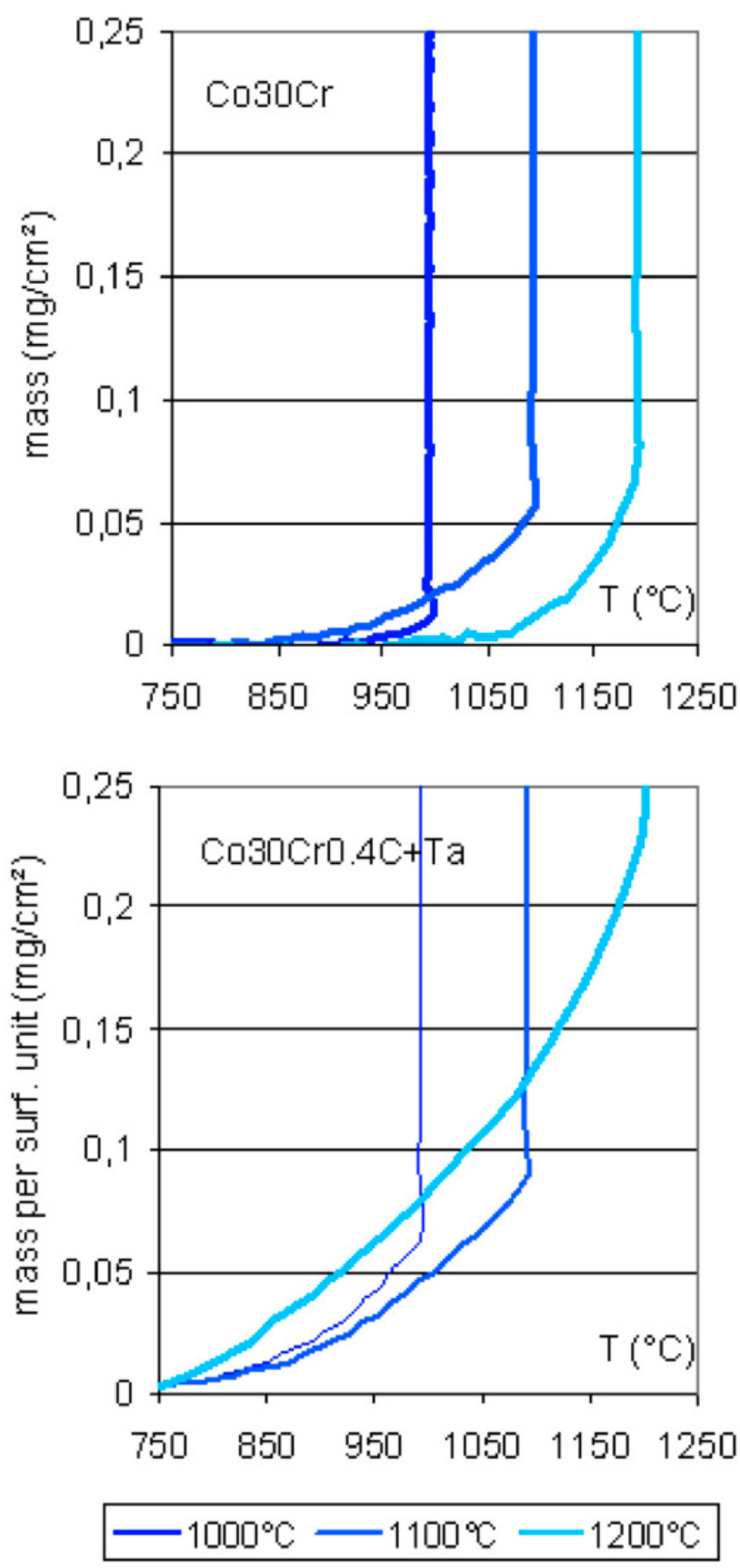

Fig. (7). Starts of mass gain due to oxidation during the last part of heating in the case of two of the four Cobalt-based alloys for the three tests (targeted isothermal temperatures equal to 1000, 1100 and $\left.1200^{\circ} \mathrm{C}\right)$. 

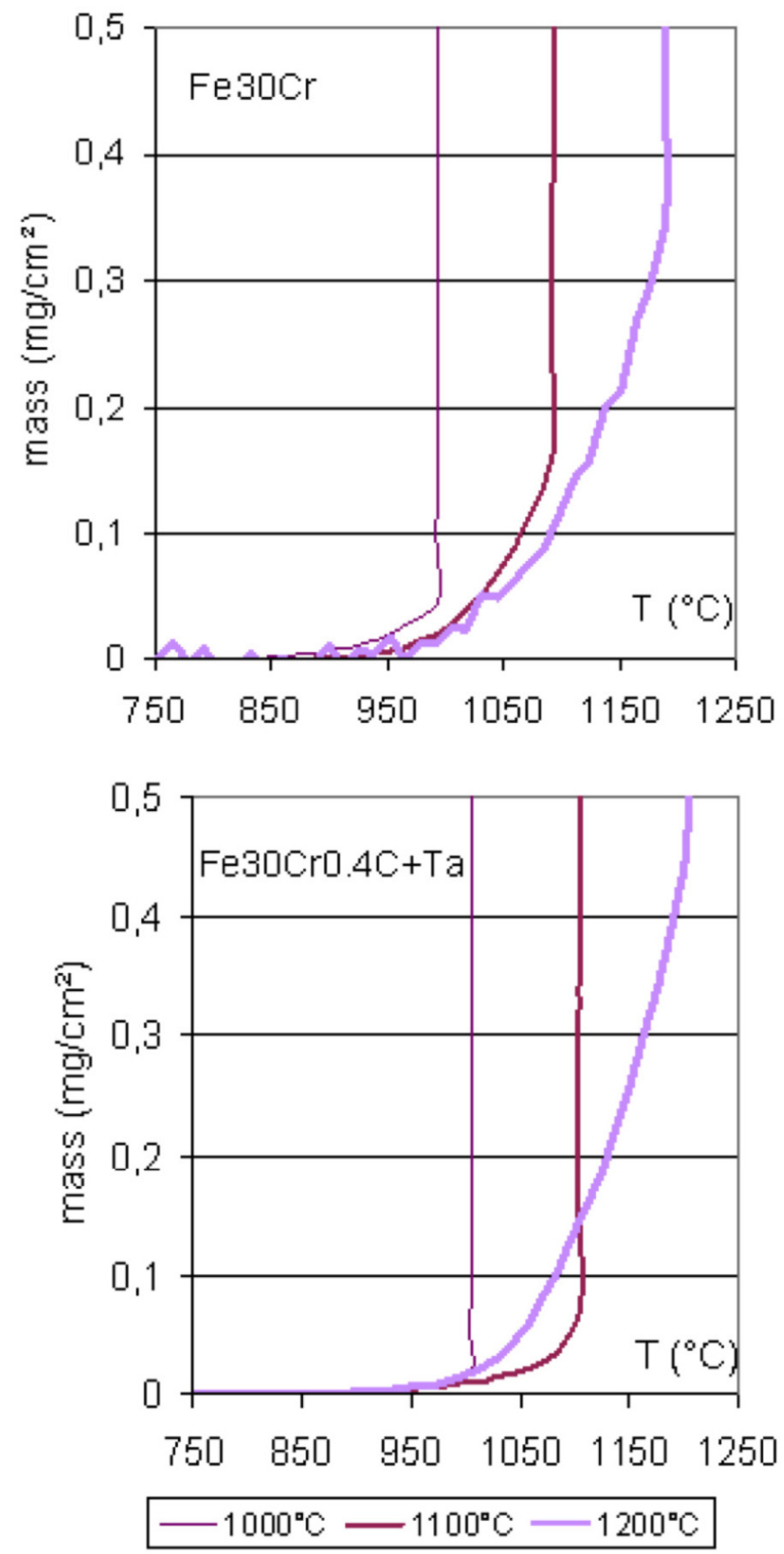

Fig. (8). Starts of mass gain due to oxidation during the last part of heating in the case of two of the four Iron-based alloys for the three tests (targeted isothermal temperatures equal to 1000,1100 and $\left.1200^{\circ} \mathrm{C}\right)$.

After correction of the thermogravimetric results from the effect of the decrease in Archimedes' thrust, one can also estimate the total mass gain achieved between the oxidation start and the moment at which temperature reaches the targeted isothermal one. Furthermore, with the thermogravimetric tests performed in this work, three results are available per alloy for $1000^{\circ} \mathrm{C}$ and two for $1100^{\circ} \mathrm{C}$ (but only one for $1200^{\circ} \mathrm{C}$ ), since one can read, on the corrected thermogravimetric curves corresponding to a targeted isothermal temperature equal to $1200^{\circ} \mathrm{C}$ (for example), also what were the mass gains when the increasing temperature was equal to $1100^{\circ} \mathrm{C}$ and to $1000^{\circ} \mathrm{C}$. The results are plotted

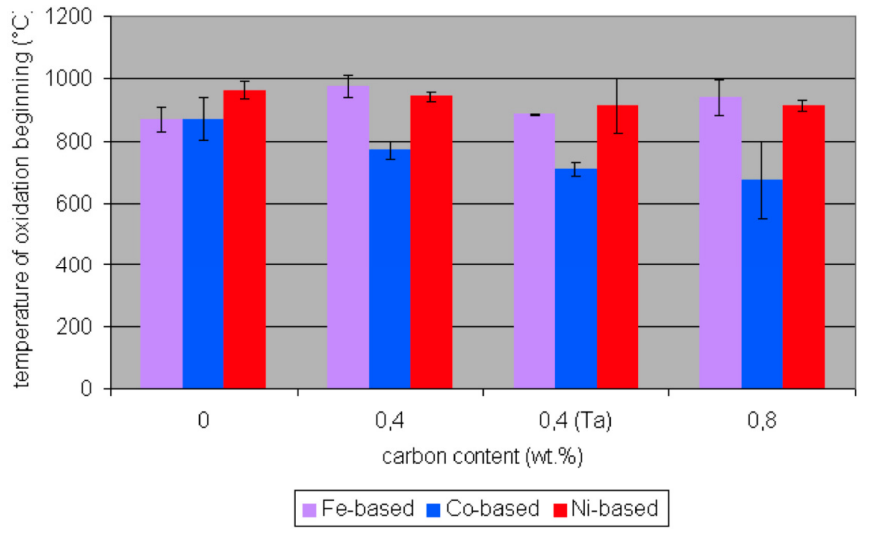

Fig. (9). Temperatures of oxidation start at heating, for all alloys (for each alloy: average values and standard deviations calculated from the three tests $\mathrm{T}_{\text {targeted }}=1000,1100$ and $1200^{\circ} \mathrm{C}$ ).

versus the contents in $\mathrm{C}$ and $\mathrm{Ta}$, in Fig. (10) for the nickelbased alloys, in Fig. (11) for the cobalt-based alloys and in Fig. (12) for the iron base alloys. The average value and standard deviation value are calculated from three results for $1000^{\circ} \mathrm{C}$ and two results for $1100^{\circ} \mathrm{C}$, while only one value is considered for $1200^{\circ} \mathrm{C}$. In all cases, the mass gain achieved at the end of heating is logically higher when the temperature of isothermal stage is higher. If only the Ta-free alloys are considered, it seems that the total mass gain during heating is more important when there is more carbon in the nickelbased alloys or cobalt-based alloys, while there is the inverse tendency for the iron-based alloys. In contrast, the effect of tantalum is the same for the three alloys families: compared to the ternary alloys with the same carbon content, the Tacontaining alloys present, at the end of heating until a same temperature, a mass gain systematically higher. The mass gain at heating's end is even higher than the one achieved for the C-richest ternary alloy for the same temperatures in the case of the nickel-based and cobalt-based alloys.

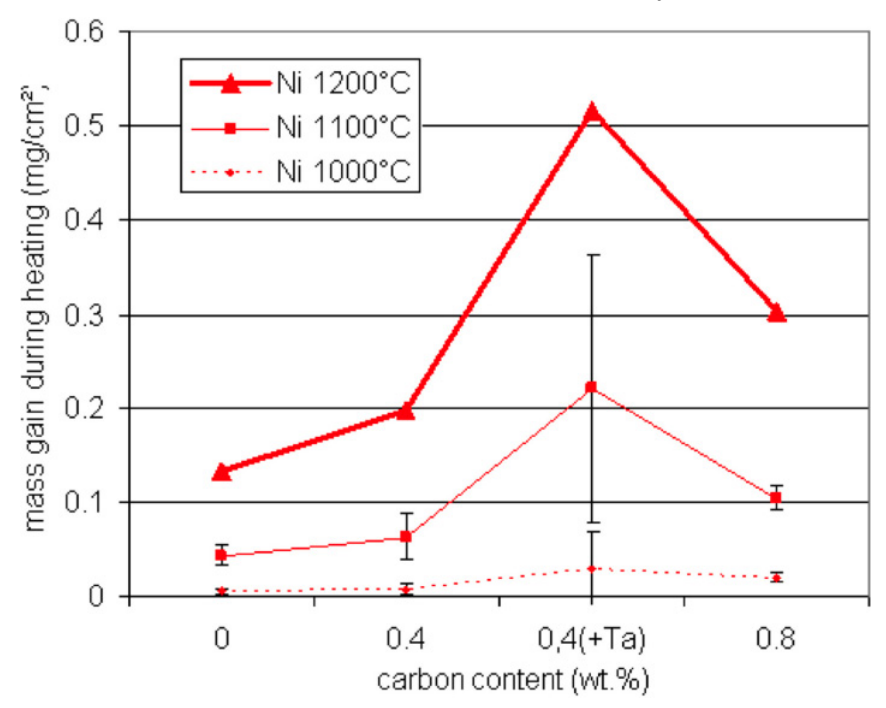

Fig. (10). Total mass gains due to oxidation during heating, for the Nickel-based alloys.

\section{DISCUSSION}

The thermogravimetry curves, more usually used for assessing the parabolic constant characterizing the 


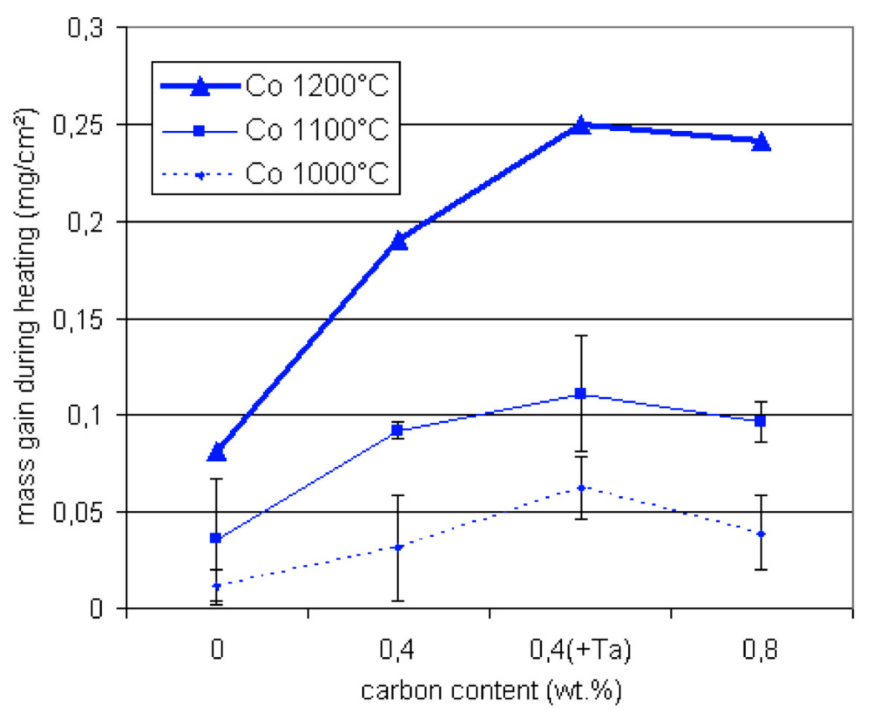

Fig. (11). Total mass gains due to oxidation during heating, for the Cobalt-based alloys.

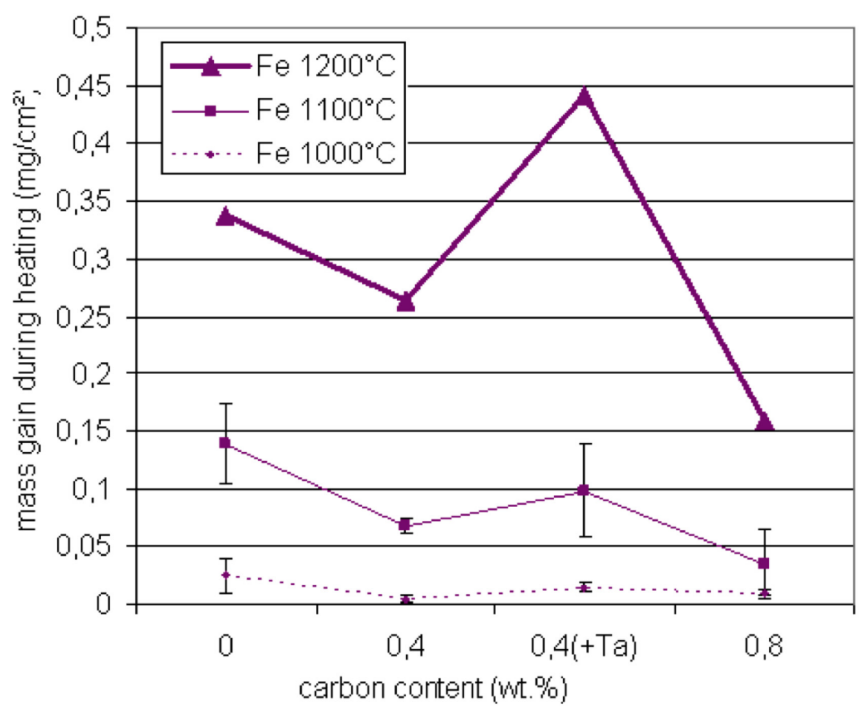

Fig. (12). Total mass gains due to oxidation during heating, for the Iron-based alloys.

isothermal oxidation, can be interesting to observe in their heating part or cooling parts for better know oxidation during heating or oxide spallation during cooling, as sometimes done in earlier studies, for example among the most recent ones: [7-12]. In the heating part, the thermogravimetric results can be firstly perturbed at low temperature by the establishing thermal equilibrium (seen on the thermogravimetric curve corresponding to an inert alumina sample as well as the real samples of alloys), and thereafter, at higher temperatures, only by the Archimedes' thrust decrease (e.g. variation of the air buoyancy). Since oxidation really begins at high temperature, only the latter phenomenon needs to be corrected in order to facilitate the detection of oxidation start, which was easily done here thanks to a variation of the Archimedes' thrust become almost linear at this level of temperature.

The temperature at which oxidation starts does not always present a good reproducibility when the three heating phases (for reaching 1000,1100 or $1200^{\circ} \mathrm{C}$ ) are considered together, as shown by the three zoomed curves per graph in
Figs. (6-8) and by the standard deviation values in the histogram in Fig. (9). The worst reproducibility was found for the cobalt alloys while the best one was observed for the iron alloys. This is to be bound with the tendency of cobalt alloys to start oxidation with nucleation and growth of $\mathrm{CoO}$ and $\mathrm{Cr}_{2} \mathrm{O}_{3}$ in microscopic neighbour areas on the sample surface (these oxide later react together to form a spinel part of the external oxide), with consequently a rapid oxidation which is detectable by mass gain measurement for lower temperatures than for the other types of alloys (Ni-based and Co-based). This is also enhanced for the cobalt alloys by the fact that the $30 \mathrm{wt} . \% \mathrm{Cr}$ present in these alloys is close to the minimal quantity of chromium for resisting high temperature oxidation. This limit is usually considered being only 20wt.\% for nickel alloys and iron alloys which are, at the early stage of oxidation, probably more rapidly covered externally by chromia. This is probably the same reason which led to oxidation start at lower temperatures for the ternary cobalt alloys when carbides are present since the precipitation of chromium carbides lowers the chromium content in the matrix (which is the main phase exposed to air in terms of surface fraction). This effect of a too low chromium content in matrix continued to act until the targeted temperatures were reached since the total mass gain at the end of heating (for a given targeted temperature) continuously increases when the carbon content increases from 0 to $0.8 \mathrm{wt} . \% \mathrm{C}$ for the Ta-free cobalt alloys, since the total mass gain observed at the end of heating, for a given targeted temperature, also increases. This increase, with the carbon content, of the total mass gain during heating also exists for the nickel alloys. It is interesting to notice that the effect of carbon (or carbides density) which was already encountered for the isothermal parabolic oxidation [13], also exists in the case of transient oxidation during the heating.

Another parameter about the alloy chemical composition influencing the start of oxidation at heating is the presence of a fourth element when it is especially oxidable: tantalum. Indeed, it is obviously the reason of the slight but significant (regarding the standard deviations) decrease in temperature of oxidation start between the two $0.4 \mathrm{wt} . \% \mathrm{C}$-containing cobalt alloys. Such effect was also seen for the nickel-based and iron-based alloys. This effect of tantalum continued to act until the targeted temperatures were reached since the total mass gain at the end of heating (for a given targeted temperature) was significantly increased for the $0.4 \mathrm{wt}$.Ccontaining alloys when 5 to $6 \mathrm{wt} . \%$ of tantalum were present in the alloys. Thus, the effect of tantalum on the transient oxidation during the heating is similar to its influence on the isothermal parabolic oxidation which was noticed in previous studies [14].

\section{CONCLUSION}

The heating parts of thermogravimetric measurements before isothermal oxidation at high temperature can be of a great interest since they allows obtaining data concerning the transient oxidation during the heating, which is rapidly replaced by the parabolic kinetic at the beginning of the usual isothermal stage which follows. Here, taking in consideration these mass variations during the heating (after correction of the mass variations due to other reasons than oxidation) has revealed the potential influences of the base element, the carbon content and the presence of an element 
easy to oxidize such tantalum, on the starting conditions and rates of oxidation before temperature becomes constant.

\section{ACKNOWLEDGEMENTS}

The author wishes to thank P. Lemoine, C. Vébert, Y. Hamini and L. Aranda for their contributions to this work.

\section{REFERENCES}

[1] Bradley EF, Eds. Superalloys: a technical guide. ASM International: Metals Park 1988.

[2] Wasielewski G E, Rapp R A; High-Temperature Oxidation. In: Sims C T, Hagel W C, Eds. The Superalloys. New York: John Wiley \& Sons 1972; pp. 287-316.

[3] Beltran A M, Shores D A; Hot Corrosion. In: Sims CT, Hagel WC, Eds. The Superalloys. New York: John Wiley \& Sons 1972; pp. 317-39.

[4] Kofstad P; High Temperature Corrosion. London: Elsevier Applied Science 1988

[5] Grisaffe S J; Coatings and protection. In: Sims C T and Hagel W C, Eds. The Superalloys, New York: John Wiley \& Sons 1972; pp. 341-70.

[6] Wagner C. The theory of the warm-up process. Z Phys Chem 1933; 21(1/2): $25-41$.
[7] Berthod P. Beginning of oxidation during heating in the case of cast nickel-based alloys containing carbides of chromium and/or tantalum. Mater Sci Ind J 2009; 5(2): 85-93.

[8] Plascencia G, Utigard T, Marin T. The oxidation resistance of copper-aluminum alloys at temperatures up to $1,000^{\circ} \mathrm{C}$. JOM 2005 ; 57(1): 80-4.

[9] Baleix S, Bernhart G, Lours P. Investigation of the spallation of oxides grown on thermally cycled heat resistant cast steels. Mater Sci Forum 2001; 1: 539-46.

[10] Pettersson RFA, Enecker J, Liu L. Role of nickel in the oxidation of $\mathrm{Fe}-\mathrm{Cr}$-Ni alloys in air-water vapour atmospheres. Mater High Temp 2005; 22(3-4): 269-81.

[11] Kartono R, Monceau D, Young DJ. Continuous thermogravimetric analysis during the cyclic oxidation of Ni-22Al-15Pt $+1 \mathrm{wt} . \% \mathrm{Hf}$ at $1200^{\circ}$ C. Scr Mater 2007; 57: 647-50.

[12] Berthod P. Thermogravimetric study of oxide spallation for chromium-rich cast cobalt-based and iron-based alloys oxidized at high temperature. Open Corr J 2009; 2: 53-62.

[13] Berthod P. Influence de l'élément de base et de la densité des carbures sur l'oxydation à haute temperature d'alliages $\mathrm{M}-30 \mathrm{Cr}$-xC $(\mathrm{M}=\mathrm{Co}, \mathrm{Ni}, \mathrm{Fe})$. Partie I : Constantes cinétiques paraboliques et de volatilization de $\mathrm{Cr}_{2} \mathrm{O}_{3}$. Ann Chimie Sci Matériaux 2008; 33(3): 225-45.

[14] Berthod P, Hamini Y, Aranda L. Influence of tantalum on the rates of high temperature oxidation and chromia volatilization for cast (Fe and/or Ni)-30Cr-0.4C alloys. Mater Sci Forum 2008; 595: 86170 